\title{
Epstein-Barr virus infection and genome polymorphisms on gastric remnant carcinoma: a meta-analysis
}

\author{
Chao Lu, Hongtao Zhang, Weihua Zhou, Xingyong Wan, Lan Li and Chaohui Yu* ${ }^{*}$
}

\begin{abstract}
Background: Previous studies reported that Epstein-Barr virus (EBV) may play a causal role in the pathogenesis of gastric remnant carcinoma (GRC). However, there was still some controversy.

Methods: Articles published until July 15, 2020, in PubMed, MEDLINE, Embase and CNKI databases were selected. According to the inclusion criteria, corresponding data of included articles were abstracted and used for statistical analysis.

Results: Thirteen papers were finally enrolled, nine of which showed the result that the risk of EBV infection rate in the $\mathrm{GRC}$ was higher than conventional gastric carcinoma $(\mathrm{OR}=5.22,95 \% \mathrm{Cl} 3.89-7.00)$. In addition, we found that EBV associated GRC (EBVaGRC) had higher rate of Billroth-II $(\mathrm{OR}=3.80,95 \% \mathrm{Cl} 1.90-7.57)$, carcinoma in anastomotic site ( $\mathrm{OR}=2.41,95 \% \mathrm{Cl} 1.27-4.56)$ and diffuse type (Lauren classification) $(\mathrm{OR}=1.97,95 \% \mathrm{Cl} 1.04-3.73)$, while sex, initial diagnosis and lymphocytic infiltration were calculated no statistical difference. By genetic polymorphism analysis, "V-val" subtype of EBNA1 (OR=21.84, 95\% Cl 11.92-31.76) and "C" subtype of BamHI-W1/I1 (OR=7.07, 95\% Cl 1.47-34.03) were observed to be highly expressed in EBVaGRC.

Conclusion: EBV infection rate in the GRC was higher. Further analysis showed that Billroth-II, carcinoma in anastomotic site and diffuse type (Lauren classification) were associated to EBVaGRC. Through analysis of EBV genome polymorphisms, we thought that " $\mathrm{V}$-val" subtype of EBNA1 and "C" subtype of BamHI-W1/I1 may become predictor of EBVaGRC.
\end{abstract}

Keywords: Epstein-Barr virus, Gastric remnant carcinoma, Clinicopathologic characteristics, Genotypes, EBV associated GRC

\section{Background}

Gastric remnant carcinoma (GRC) is defined as a carcinoma occurring in the gastric stump 5 or more years after distal gastric resection for benign disease such as gastric ulcer and duodenal ulcer or gastric malignancy $[1,2]$. The etiology and pathogenesis associated with

${ }^{*}$ Correspondence: zyyyych@zju.edu.cn

Department of Gastroenterology, The First Affiliated Hospital, College of Medicine, Zhejiang University, 79 Qingchun Road, Hangzhou 310003, China malignant transformation in the gastric stump are poorly understood.

An oncogenic association between gastric carcinoma (GC) and Epstein-Barr virus (EBV) is well known [3]. EBV-associated-gastric carcinoma (EBVaGC) prevalence varied from 2 to $18 \%$ in different countries [4]. Lee et al. have reported a meta-analysis indicating that the clinicopathological and molecular characteristics of EBVaGC were quite different from those of conventional gastric adenocarcinoma [5]. As early as 1994, Yamamoto et al. have published the relationship between GRC and EBV,

(c) The Author(s) 2020. This article is licensed under a Creative Commons Attribution 4.0 International License, which permits use, sharing, adaptation, distribution and reproduction in any medium or format, as long as you give appropriate credit to the original author(s) and the source, provide a link to the Creative Commons licence, and indicate if changes were made. The images or other third party material in this article are included in the article's Creative Commons licence, unless indicated otherwise in a credit line to the material. If material is not included in the article's Creative Commons licence and your intended use is not permitted by statutory regulation or exceeds the permitted use, you will need to obtain permission directly from the copyright holder. To view a copy of this licence, visit http://creativeco mmons.org/licenses/by/4.0/. The Creative Commons Public Domain Dedication waiver (http://creativecommons.org/publicdomain/ zero/1.0/) applies to the data made available in this article, unless otherwise stated in a credit line to the data. 
which revealed that the EBV may play an important role in the carcinogenesis of GRC [6].

EBV is a gamma herpesvirus, which is a ubiquitous cause of infection in humans worldwide. Evidence of prior infection is present in adults throughout the world, with over $90 \%$ showing a serologic response [7]. In addition to GC, EBV is also closely related to Burkitt's lymphoma (BL), Hodgkin lymphoma (HD) and nasopharyngeal carcinoma (NPC) [8-10]. The exact role of EBV in the pathogenesis of EBV-associated-gastric remnant carcinoma (EBVaGRC) remains to be determined. Previous study has reported that different genotype EBV expressed in GRC, which may play a key role in the pathogenesis of EBVaGRC [11]. However, there were still some controversies.

In this study, we aimed to explore whether there was a higher EBV infection rate in GRC compared to conventional GC (CGC). The exploration of related clinicopathologic factors such as Lauren classification between EBVaGRC and EBV-negative-gastric remnant carcinoma (EBVnGRC) were also one of the purposes in the study. In addition, we also analyzed EBV genome polymorphisms in EBVaGRC in order to reveal some relevance.

\section{Materials and methods}

\section{Data selection and data abstraction}

We searched articles published until July 15, 2020, in the PubMed, MEDLINE and Embase databases, and also searched Chinese database named CNKI. In order to cover as many articles as possible, following terms were used to search: ((residual gastric cancer) OR (residual gastric carcinoma) OR (gastric remnant carcinoma) OR (gastric remnant cancer) OR (gastric stump cancer) OR (gastric stump carcinoma)) AND ((Epstein-Barr virus) OR EBV OR (EB virus) OR EBNA1 OR EBNA2 OR EBNA3C OR (30 bp deletion in LMP1) OR BamHI-F OR BamHI-W1/I1). EBNA1, EBNA2, EBNA3C, 30 bp deletion in LMP1, BamHI-F and BamHI-W1/I1 are all EBV genotypes. After the primary election, the inclusion and exclusion criteria were used for the next screening. Articles would be included if they met all the following criteria: (1) Published as full articles; (2) Related data of GRC and EBV can be calculated; (3) The initial malignant tumor was cured before GRC; (4) EBV positivity was identified by in situ hybridization; (5) No other coexisting malignant tumors. Articles which did not meet the above criteria or duplicate publication were excluded.

Main study characteristics for analysis such as EBVaGRC data, EBV genotypes data were extracted to Microsoft Excel (2019 edition; Microsoft, Redmond, WA, USA) for effective organization. In addition, clinical features such as reconstruction style, initial diagnosis, location of GRC, Lauren classification, sex of patients, lymphocytic infiltration between EBVaGRC and EBVnGRC were also abstracted to assess risk factors.

Studies were independently screened by title and abstract by CL and XY. Both authors subsequently performed full articles. If there was a disagreement, XYW would evaluate the disagreement again and form a final result after the trade. Risk of bias and Quality assessment were assessed using elements of the STROBE checklist for studies included [12]. Once an overall gene effect was confirmed, the genetic model-free approach was used to estimate the genetic effects and mode of inheritance [13]. In addition, the work was conducted in accordance with the Preferred Reporting Items for Systematic Reviews and Meta-Analyses (PRISMA) statement [14].

\section{Statistical analysis}

The odds ratio (OR) combined 95\% confidence intervals (CIs) was used to describe dichotomous variable, which contained EBVaGRC data, EBVnGRC data, clinical features and genome polymorphisms data. For individual studies of genome polymorphisms with no events in one or both groups, a continuity correction of 0.5 would be added to each cell for each effect measure, as implemented in Review Manager 4.2 [15], and OR was used to describe it. Statistical heterogeneity was assessed by the $\mathrm{I}^{2}$ statistic and Cochran's Q-test. Then pooled estimates were obtained using the fixed-model (Mantel and Haenszel) method (if $\left.\mathrm{I}^{2} \leq 50 \%, \mathrm{P}>0.1\right)$ or random-model $(\mathrm{M}-\mathrm{H}$ heterology) method (if $\mathrm{I}^{2}>50 \%, \mathrm{P} \leq 0.1$ ) [16]. What we need to explain here was that random-model method was more widely used. Regardless of heterogeneity of pooled estimates, random-model method can be selected. When heterogeneity was high, random-model method was the only choice. While heterogeneity was low, both randommodel and fixed-model model can be selected. In this study, fixed-model model was selected [16]. Furthermore, we used sensitivity analysis, which was conducted by metainf application, to evaluate whether the meta-analysis results were stable and reliable. Metainf investigated the influence of a single study on the overall meta-analysis estimate. And this command showed graphically the results of an influence analysis. Publication bias was estimated by Begg's test $(\mathrm{P}>0.05$ suggests no publication bias). All analyses were carried out through the application of STATA 15 (StataCorp., College Station, TX, USA).

\section{Results}

\section{Basic characteristics}

Our search identified 2031 related articles, of which 13 papers finally enrolled according to the inclusion criteria [6, 11, 17-27]. The flowchart describing the process of this study selection was shown in Fig. 1. Studies were mainly concentrated in Asia, while only 


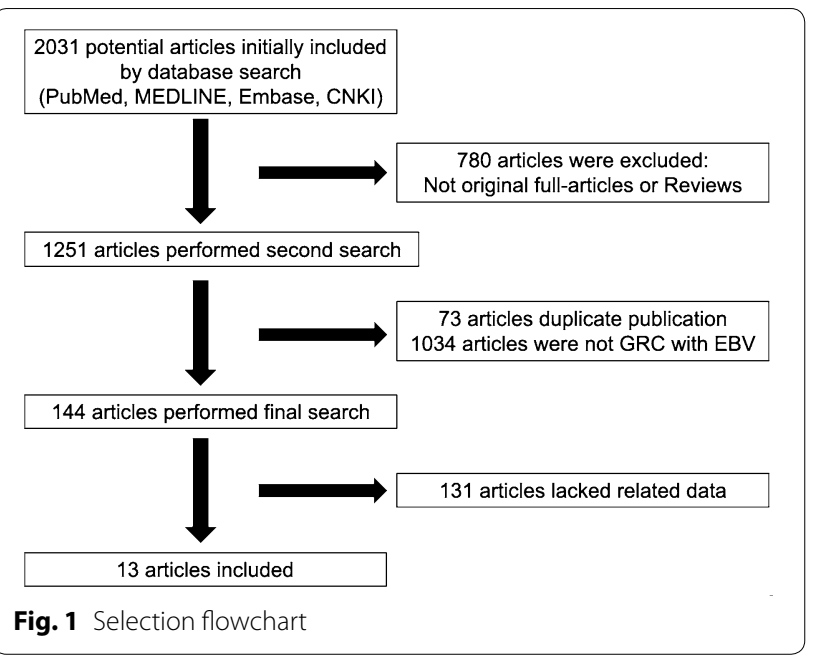

two articles in Europe were enrolled. In addition, three articles referred to different EBV genotypes between GRC and control. Based on different clinicopathologic characteristics, related data were chosen to analyze. Heterogeneity of most analysis in this study was small, so the fixed-model method was the main choice.

\section{EBV infection in GRC and CGC}

Nine articles reported data about EBV infection in GRC and CGC. The main characteristics were listed in Table 1. The total EBV infection rate in GRC was $25.14 \%$ (91/362), while it was $2.25 \%$ (348/15433) in CGC. Compared to infection rate in CGC, the risk of EBV infection rate in the GRC was 5.22 times $\left(\mathrm{OR}=5.22,95 \%\right.$ CI $\left.3.89-7.00, \mathrm{I}^{2}=14.7 \%, \mathrm{P}=0.312\right)$ (Fig. 2). It could be seen that EBV plays a more important role in the pathogenesis of GRC than CGC.

\section{Clinicopathologic characteristics between EBVaGRC and EBVnGRC}

According to the limited information provided in the articles, we analyzed clinicopathologic characteristics on reconstruction style after surgery (6 studies), initial diagnosis (3 studies), location of GRC (6 studies), Lauren classification (6 studies), sex of patients (5 studies), lymphocytic infiltration (3 studies). The main results were listed in Additional file 1: Table S1-Table S6. Reconstruction style, location of GRC and Lauren classification had statistic difference. The amount of Billroth-II was 3.8 times in EBVaGRC that of EBVnGRC (OR $=3.80,95 \% \mathrm{CI}$ 1.90-7.57, $\mathrm{I}^{2}=0, \mathrm{P}=0.463$ ) (Fig. 3a). Compared to EBVnGRC, EBVaGRC was 2.41 times more likely to become cancerous in the anastomotic site $(\mathrm{OR}=2.41,95 \% \mathrm{CI}$ $1.27-4.56, \mathrm{I}^{2}=40.4 \%, \mathrm{P}=0.136$ ) (Fig. $3 \mathrm{~b}$ ). In addition, for Lauren classification, diffuse type was more common in EBVaGRC, which was 1.97 times compared to EBVnGRC $\left(\mathrm{OR}=1.97,95 \%\right.$ CI $\left.1.04-3.73, \mathrm{I}^{2}=24.6 \%, \mathrm{P}=0.25\right)$ (Fig. 3c). However, initial diagnosis $(\mathrm{OR}=3.0,95 \% \mathrm{CI}$ $\left.0.83-10.88, \mathrm{I}^{2}=0, \mathrm{P}=0.467\right)$, sex $(\mathrm{OR}=2.1,95 \% \mathrm{CI} 0.81-$ $\left.5.47, \mathrm{I}^{2}=34.9 \%, \mathrm{P}=0.188\right)$ and lymphocytic infiltration $\left(\mathrm{OR}=0.31,95 \%\right.$ CI $\left.0.08-1.13, \mathrm{I}^{2}=56.6 \%, \mathrm{P}=0.10\right)$ had no statistic difference between EBVnGRC and EBVaGRC (Fig. 3d-f).

\section{EBV genotypes between GRC and control}

Three articles referred EBV genotypes, which included EBNA1, EBNA2, EBNA3C, 30 bp deletion in LMP1, BamHI-F and BamHI-W1/I1. Of these, EBNA1, 30 bp deletion in LMP1, BamHI-F and BamHI-W1/I1 were reported by two articles. The main characteristics were listed in Table 2. EBNA2 and EBNA3C were no statistic difference between GRC and control reported by one article respectively $(P=0.624, P=0.159$, respectively). By meta-analysis, we found that "V-val" subtype of EBNA1 $\left(\mathrm{OR}=21.84,95 \%\right.$ CI $\left.11.92-31.76, \mathrm{I}^{2}=93.3 \%, \mathrm{P}<0.001\right)$ and "C" subtype of BamHI-W1/I1 (OR $=7.07,95 \% \mathrm{CI}$

Table 1 The main characteristics about EBV infection in GRC and CGC

\begin{tabular}{|c|c|c|c|c|c|c|c|}
\hline Author & Country & Year & GRC, EBV+ & GRC, EBV- & CGC, EBV+ & CGC, EBV- & OR \\
\hline Choi & Korea & 2012 & 4 & 106 & 62 & 10,556 & 6.42 \\
\hline Yamamoto & Japan & 1994 & 13 & 35 & 116 & 1709 & 5.47 \\
\hline Chang & Korea & 2003 & 5 & 21 & 12 & 260 & 5.16 \\
\hline Liu & China & 2016 & 10 & 36 & 3 & 41 & 3.80 \\
\hline Kaizaki & Japan & 2005 & 18 & 60 & 46 & 472 & 3.08 \\
\hline Baas & Netherlands & 1998 & 9 & 17 & 2 & 22 & 5.82 \\
\hline Chang & Korea & 2000 & 5 & 21 & 17 & 288 & 4.03 \\
\hline Huang & Taiwan, China & 2014 & 10 & 21 & 42 & 947 & 10.74 \\
\hline Huang & Taiwan, China & 2019 & 17 & 45 & 48 & 1138 & 8.96 \\
\hline
\end{tabular}

EBV Epstein-Barr virus, GRC gastric remnant carcinoma, CGC conventional gastric carcinoma, OR odds ratio 


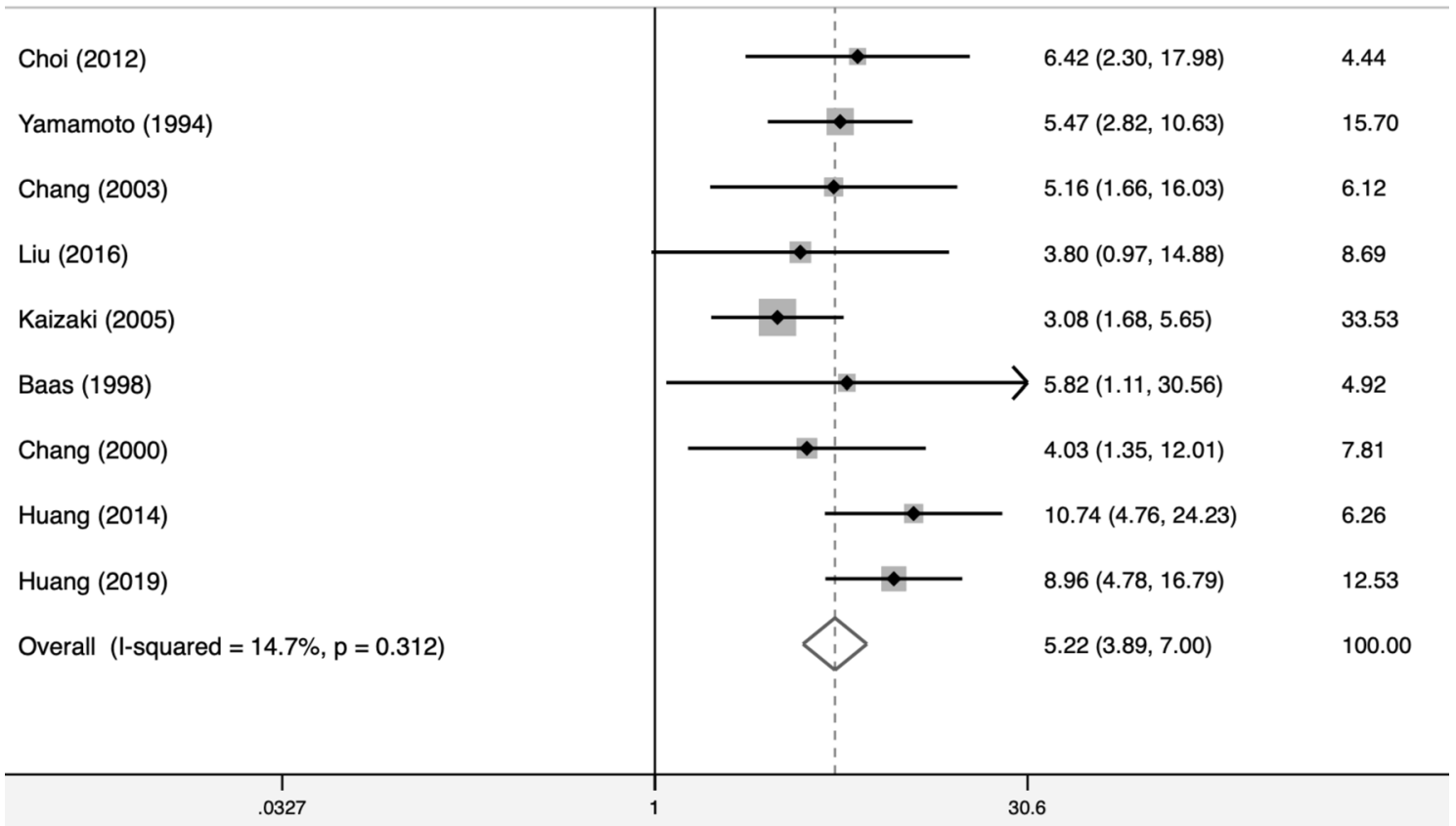

Fig. 2 Compared to infection rate in CGC, the risk of EBV infection rate in the GRC was 5.22 times $\left(\mathrm{OR}=5.22,95 \% \mathrm{Cl} 3.89-7.00, \mathrm{I}^{2}=14.7 \%, \mathrm{P}=0.312\right)$

1.47-34.03, $\left.\mathrm{I}^{2}=0, \mathrm{P}=0.682\right)$ occupied larger proportion in GRC than control (Fig. 4). Nevertheless, subtype of BamHI-F had no difference between GRC and control (Fig. 4).

\section{Publication bias and sensitivity analysis}

Begg's test showed that there was no publication bias in this meta-analysis, including EBV infection in GRC and CGC $(P=0.917)$, reconstruction style $(P=0.851)$, initial diagnosis $(P=0.296)$, location of GRC $(P=0.707)$, Lauren classification $(\mathrm{P}=0.851)$, sex of patients $(\mathrm{P}=0.462)$ and lymphocytic infiltration $(\mathrm{P}=0.602)$ (Additional file 2). In addition, sensitivity analysis results showed that some results of dichotomous variable including EBV infection comparisons and clinicopathologic characteristics comparisons were fluctuant, but they were still stable and reliable (Additional file 3).

\section{Discussion}

In this study, we firstly reported that EBV infection rate in the GRC was higher than CGC. EBVaGRC had higher rate of Billroth-II, carcinoma in anastomotic site and diffuse type (Lauren classification) compared to EBVnGRC, but it is not associated with sex, initial diagnosis and lymphocytic infiltration. In addition, EBV genome polymorphisms analysis showed that expression of "V-val" subtype of EBNA1 and "C" subtype of BamHIW1/I1 were higher in EBVaGRC than control. We comprehensively analyzed EBV infection and genome polymorphisms on GRC through systematic review and meta-analysis for the first time.

Up until now, the role of EBV in carcinogenesis of the gastric remnant or stomach is not completely understood. It has been suggested that EBVaGC have distinct molecular characteristics, as well as clinicopathological characteristics [5]. The distinguish in EBVaGRC was also found in this study. The loss of $p 16$ protein [28], or overexpression of bcl-2 [29] was detected in EBV-infected tumors or EBVaGC, which may be related to the pathogenesis of GRC. In addition, Imai et al. revealed that EBV is uniformly present in all carcinoma cells of GRC, but nearly negative in normal epithelium or stroma [3]. The findings indicated that EBV infection may influence carcinogenesis, perhaps triggering a clonal expansion of infected cells [3].

In the study, three clinicopathological factors were observed related to EBVaGRC. EBVaGRC was more likely to occur in anastomotic sites and after Billroth-II 


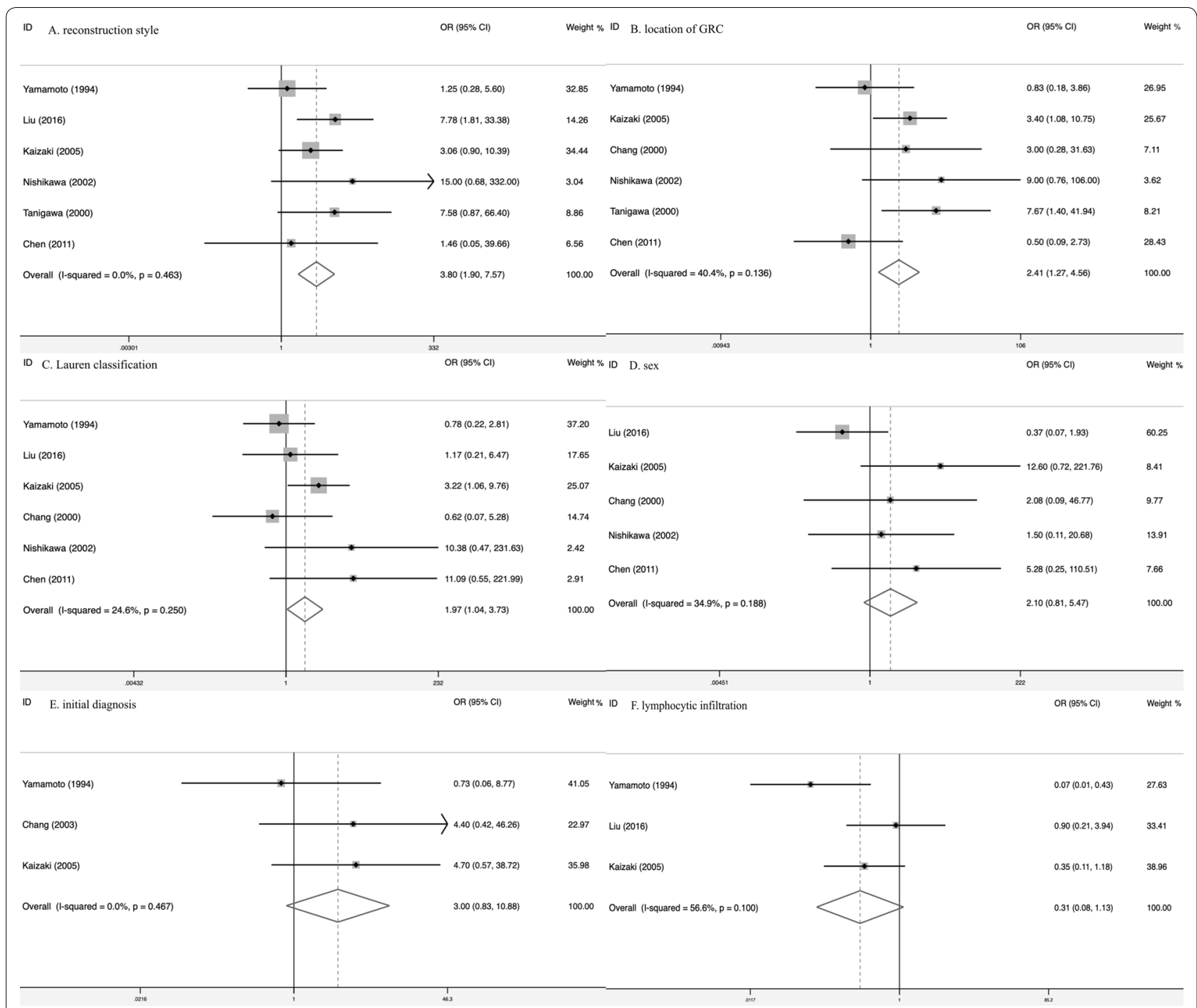

Fig. 3 clinicopathologic characteristics between EBVaGRC and EBVnGRC (a reconstruction style; b location of GRC; c Lauren classification; d sex; e initial diagnosis; $\mathbf{f}$ lymphocytic infiltration)

reconstruction. The changes of anatomical circumstances may be the main factor. The reflux of bile and pancreatic juice is more common in Billroth-II reconstruction, which can directly change the physiological environment and $\mathrm{pH}$-value of the gastric remnant. These could act as a cofactor mediating EBV infection of the epithelial cells or facilitate EBV entering the mucosa epithelia, for instance by inducing fusion of EBV carrying B cells and epithelial cells. In addition, more diffuse type of GRC can be found with EBV infection. This type of cancer usually presents shorter duration and worse prognosis compared with the intestinal type [30]. Therefore, EBV infection may aggravate the severity of the cancer. Although some articles have found a correlation between sex, initial diagnosis, lymphocytic infiltration and EBVaGRC, the results of this study revealed no correlation by data Integration.

In addition, we paid attention to survival rate of GRC, but no articles reported it. Liu et al. reported that EBV had a favorable impact on GC patient's survival, especially in an Asian population [31]. In GRC, whether EBV can influence the survival rate, we need more studies to support evidence.

We also found "V-val" subtype of EBNA1 and "C" subtype of BamHI-W1/I1 were higher expressed in EBVaGRC. These two subtypes may be closely related to oncogenesis and be as potential disease predictor. It is 
Table 2 The main characteristics of EBV genotypes between GRC and control

\begin{tabular}{|c|c|c|c|c|c|c|}
\hline \multirow{2}{*}{$\begin{array}{l}\text { Genotype } \\
\text { EBNA1 }\end{array}$} & \multirow[t]{2}{*}{ Author } & \multirow[t]{2}{*}{ Year } & \multicolumn{4}{|l|}{ Subtype } \\
\hline & & & $\begin{array}{l}\text { Case "V-val" (B95.8, } \\
\text { 109409) }\end{array}$ & $\begin{array}{l}\text { Case "V-leu" (B95.8, } \\
109408 \sim 109410)\end{array}$ & $\begin{array}{l}\text { Control "V-val" } \\
\text { (B95.8, 109409) }\end{array}$ & $\begin{array}{l}\text { Control “V-leu” (B95.8, } \\
\text { 109408 109410) }\end{array}$ \\
\hline & Liu & 2016 & 9 & 0 & 3 & 0 \\
\hline & Chen & 2012 & 0 & 4 & 15 & 9 \\
\hline \multirow[t]{2}{*}{ EBNA2 } & & & Case"1" (497 bp) & Case "2" (-) & Control "1" (497 bp) & Control "2" (-) \\
\hline & Liu & 2016 & 13 & 0 & 3 & 0 \\
\hline \multirow[t]{2}{*}{ EBNA3C } & & & Case "A" (153 bp) & Case"B" (246 bp) & Control "A" (153 bp) & Control "B" (246 bp) \\
\hline & Chen & 2011 & 8 & 0 & 12 & 4 \\
\hline \multirow[t]{3}{*}{ BamHI-F } & & & Case "F" (198 bp) & Case "f" (127+ 71 bp) & Control "F" (198 bp) & Control "f" (127 + 71 bp) \\
\hline & Liu & 2016 & 13 & 0 & 3 & 0 \\
\hline & Chen & 2011 & 8 & 1 & 16 & 3 \\
\hline \multirow[t]{3}{*}{ BamHI-W1/I1 } & & & Case "C" (205 bp) & Case "D" (130 + 75 bp) & Control "C" (205 bp) & Control "D" (130+75 bp) \\
\hline & Liu & 2016 & 9 & 4 & 1 & 2 \\
\hline & Chen & 2011 & 6 & 2 & 4 & 12 \\
\hline \multirow[t]{3}{*}{30 bp deletion in LMP1 } & & & Case "del" (189 bp) & Case "wt" (219 bp) & Control "del" (189 bp) & Control "wt" (219 bp) \\
\hline & Liu & 2016 & 12 & 1 & 3 & 0 \\
\hline & Chen & 2011 & 8 & 0 & - & - \\
\hline
\end{tabular}

GRC gastric remnant carcinoma

known that EBNA1 can induce genomic instability and reactive oxygen species (ROS)-mediated DNA damage response [32], which may act as a potential oncogene [33]. EBNA1 contains two prototypes (P-ala and P-thr) and three variants (V-pro, V-leu and V-val) [34]. It was reported that in EBV-associated neoplasms, "V-val" was predominant in individuals from Asian regions [35], while NPC, EBVaGC and nasal NK/T cell lymphoma are more prevalent in this area [36]. This phenomenon may suggest that "V-val" subtype might be more aggressive than other subtypes. The possible reason was that most of amino acid alterations of "V-val" subtype (codons $439,487,499,502,524,528$ and 533) were located in the function domains of EBNA1, which contained DNA binding domain (aa 459,487), dimerization domain (aa 501,532) and transactivation domain (aa 450,641) [26]. Thus "V-val" subtype was more likely to cause changes of EBNA1's function. In addition, previous studies revealed that "C" subtype prevails in NPC patients from Southern China where incidence of NPC is high. It was suggested that the presence of "C" subtype is also associated with oncogenesis. Therefore, "V-val" subtype and "C" subtype can be tested to predict high risk of EBVaGRC.

Although we have achieved some encouraging results, this article still had some defects. First, included articles had limitations due to article source and type. Articles were mainly from the Asian region and had no global representation. In addition, we can only clarify the relationship between EBV and GRC, but there was not enough evidence of causality. Enough randomized controlled trials (RCTs) were needed to clarify the causality. Second, the credibility of results was weakened because of insufficient data, especially analysis of EBV genome polymorphisms. Third, since the ORs of the included studies were crude ORs which were calculated by authors, there was of some heterogeneity. This part of heterogeneity cannot be ruled out, because we cannot obtain data directly from authors. And next, in this study, it was not certain that GRC originated from a recurrence of the previous GC or a "de novo" EBV-related GC. Homology of cancer is also crucial for patient treatment and follow-up. Finally, we didn't know whether EBV eradication can change the process of GRC. If EBV eradication weakened oncogenesis of gastric remnant, it will provide strong evidence that EBV is an important causative agent to GRC. Such articles were really needed.

\section{Conclusion}

In conclusion, Compared to CGC, EBV infection rate in the GRC was higher. Further analysis showed that the ratio of Billroth-II, carcinoma in anastomotic site and diffuse type (Lauren classification) were higher in EBVaGRC, which were clinicopathologic characteristics of EBVaGRC. Through analysis of EBV genome polymorphisms, "V-val" subtype of EBNA1 and "C" subtype of BamHI-W1/I1 may become predictor of EBVaGRC, and genetic test of these two can guide us to conduct early GRC intervention. 


\begin{tabular}{|c|c|c|c|}
\hline Liu (2016) & & $27.00(22.87,31.13)$ & 49.02 \\
\hline Chen (2012) & & $16.88(13.82,19.93)$ & 50.98 \\
\hline Overall (I-squared $=93.3 \%, p=0.000$ ) & & $21.84(11.92,31.76)$ & 100.00 \\
\hline $\begin{array}{l}-31.8 \\
-1\end{array}$ & & 1.8 & \\
\hline ID $\quad$ B. BamHI-W1/I1 & & OR $(95 \% \mathrm{Cl})$ & Weight \\
\hline
\end{tabular}

Liu (2016)

Chen (2011)

Overall (I-squared $=0.0 \%, p=0.682$ )

Liu (2016)

Chen (2011)

Overall (I-squared $=100.0 \%, p=0.000)$

ID C. BamHI-F
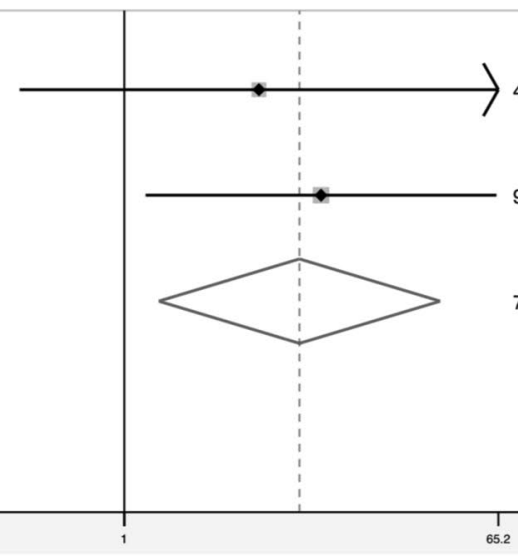

ES $(95 \% \mathrm{Cl})$

Weight $\%$

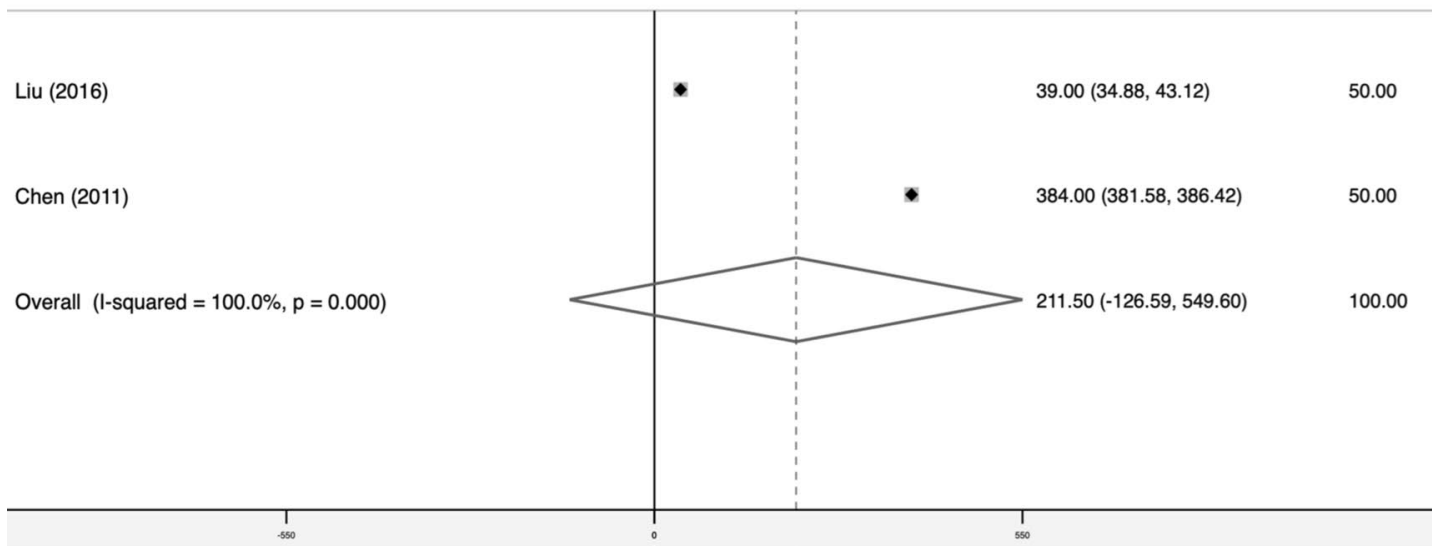

Fig. 4 the difference of ENBA1, BamHI-W1/I1 and BamHI-F between EBVaGRC and control 


\section{Supplementary information}

Supplementary information accompanies this paper at https://doi. org/10.1186/s12935-020-01498-z.

Additional file 1. The main results of clinicopathologic characteristics on reconstruction style after surgery, initial diagnosis, location of GRC, Lauren classification, sex of patients, and lymphocytic infiltration.

Additional file 2. Begg's test of EBV infection and clinicopathologic characteristics.

Additional file 3. Sensitivity analysis results of EBV infection comparisons and clinicopathologic characteristics comparisons.

\section{Abbreviations}

EBV: Epstein-Barr virus; GRC: Gastric remnant carcinoma; CGC: Conventional gastric carcinoma; EBVaGC: EBV-associated-gastric carcinoma; EBVaGRC : EBV-associated-gastric remnant carcinoma; EBVnGRC: EBV-negative-gastric remnant carcinoma.

\section{Authors' contributions}

$\mathrm{CL}$ designed research; $\mathrm{CL}$ and $\mathrm{WZ}$ searched articles and collected data; XW evaluated the disagreement; LL performed the statistical analysis; $C L$ wrote the paper; $\mathrm{CY}$ and $\mathrm{HZ}$ revised the paper. All authors read and approved the final manuscript.

\section{Funding}

Not applicable.

\section{Availability of data and materials}

The datasets used and/or analysed during the current study are available from the corresponding author on reasonable request.

\section{Ethics approval and consent to participate}

Not applicable.

\section{Consent for publication}

Not applicable.

\section{Competing interests}

The authors declare that they have no competing interests.

Received: 7 November 2019 Accepted: 13 August 2020

Published online: 18 August 2020

\section{References}

1. Safatle-Ribeiro AV, Ribeiro U Jr, Reynolds JC. Gastric stump cancer: what is the risk? Digestive diseases (Basel, Switzerland). 1998;16:159-68.

2. Kaminishi M, Shimizu N, Yamaguchi $H$, et al. Different carcinogenesis in the gastric remnant after gastrectomy for gastric cancer. Cancer. 1996;77:1646-53.

3. Imai S, Koizumi S, Sugiura M, et al. Gastric carcinoma: monoclonal epithelial malignant cells expressing Epstein-Barr virus latent infection protein. Proc Natl Acad Sci USA. 1994:91:9131-5.

4. Akiba S, Koriyama C, Herrera-Goepfert R, et al. Epstein-Barr virus associated gastric carcinoma: epidemiological and clinicopathological features. Cancer Sci. 2008;99:195-201.

5. Lee JH, Kim SH, Han SH, et al. Clinicopathological and molecular characteristics of Epstein-Barr virus-associated gastric carcinoma: a meta-analysis. J Gastroenterol Hepatol. 2009;24:354-65.

6. Yamamoto $N$, Tokunaga M, Uemura Y, et al. Epstein-Barr virus and gastric remnant cancer. Cancer. 1994;74:805-9.

7. Cohen Jl. Epstein-Barr virus infection. New Engl J Med. 2000;343:481-92.

8. Bornkamm GW. Epstein-Barr virus and the pathogenesis of Burkitt's lymphoma: more questions than answers. Int J Cancer. 2009;124:1745-55.
9. Niedobitek G. Epstein-Barr virus infection in the pathogenesis of nasopharyngeal carcinoma. MP. 2000;53:248-54.

10. Thompson MP, Kurzrock R. Epstein-Barr virus and cancer. Clin Cancer Res. 2004; 10:803-21.

11. Liu S, Zhao Z, Han L, et al. Epstein-Barr virus infection in gastric remnant carcinoma and recurrent gastric carcinoma in Qingdao of Northern China. PLoS ONE. 2016:11:e0148342.

12. Vandenbroucke JP, von Elm E, Altman DG, et al. Strengthening the reporting of observational studies in epidemiology (STROBE): explanation and elaboration. PLoS medicine. 2007;4:e297.

13. Minelli C, Thompson JR, Abrams KR, et al. Bayesian implementation of a genetic model-free approach to the meta-analysis of genetic association studies. Stat Med. 2005;24:3845-61.

14. Liberati A, Altman DG, Tetzlaff J, et al. The PRISMA statement for reporting systematic reviews and meta-analyses of studies that evaluate health care interventions: explanation and elaboration. PLoS medicine. 2009;6:e1000100

15. The Cochrane Collaboration. RevMan 42 User Guide. Oxford: The Cochrane Collaboration.

16. Higgins JP, Thompson SG. Quantifying heterogeneity in a meta-analysis. Stat Med. 2002;21:1539-58.

17. Choi MG, Jeong JY, Kim KM, et al. Clinical significance of gastritis cystica profunda and its association with Epstein-Barr virus in gastric cancer. Cancer. 2012;118:5227-33.

18. Chang MS, Lee HS, Kim HS, et al. Epstein-Barr virus and microsatellite instability in gastric carcinogenesis. J Pathol. 2003;199:447-52.

19. Kaizaki Y, Hosokawa O, Sakurai S, et al. Epstein-Barr virus-associated gastric carcinoma in the remnant stomach: de novo and metachronous gastric remnant carcinoma. J Gastroenterol. 2005;40:570-7.

20. Baas IO, van Rees BP, Musler A, et al. Helicobacter pylori and Epstein-Barr virus infection and the p53 tumour suppressor pathway in gastric stump cancer compared with carcinoma in the non-operated stomach. J Clin Pathol. 1998;51:662-6.

21. Chang MS, Lee JH, Kim JP, et al. Microsatellite instability and Epstein-Barr virus infection in gastric remnant cancers. Pathol Int. 2000;50:486-92.

22. Huang SC, Ng KF, Chen KH, et al. Prognostic factors in Epstein-Barr virusassociated stage I-III gastric carcinoma: implications for a unique type of carcinogenesis. Oncol Rep. 2014;32:530-8.

23. Huang SC, Ng KF, Yeh TS, et al. Subtraction of Epstein-Barr virus and microsatellite instability genotypes from the Lauren histotypes: Combined molecular and histologic subtyping with clinicopathological and prognostic significance validated in a cohort of 1248 cases. International journal of cancer. 2019

24. Nishikawa J, Yanai H, Hirano A, et al. High prevalence of Epstein-Barr virus in gastric remnant carcinoma after Billroth-II reconstruction. Scand J Gastroenterol. 2002;37:825-9.

25. Tanigawa $\mathrm{H}$, Uesugi $\mathrm{H}$, Mitomi $\mathrm{H}$, et al. Possible association of active gastritis, featuring accelerated cell turnover and p53 overexpression, with cancer development at anastomoses after gastrojejunostomy. Comparison with gastroduodenostomy. Am J Clin Pathol. 2000;1 14:354-63.

26. Chen JN, Zhang NN, Jiang Y, et al. Variations of Epstein-Barr virus nuclear antigen 1 in Epstein-Barr virus-associated gastric carcinomas from Guangzhou, southern China. PLoS ONE. 2012:7:e50084.

27. Chen JN, Jiang Y, Li HG, et al. Epstein-Barr virus genome polymorphisms of Epstein-Barr virus-associated gastric carcinoma in gastric remnant carcinoma in Guangzhou, southern China, an endemic area of nasopharyngeal carcinoma. Virus Res. 2011;160:191-9.

28. Schneider BG, Gulley ML, Eagan P, et al. Loss of p16/CDKN2A tumor suppressor protein in gastric adenocarcinoma is associated with Epstein-Barr virus and anatomic location in the body of the stomach. Hum Pathol. 2000;31:45-50.

29. Kume T, Oshima K, Shinohara T, et al. Low rate of apoptosis and overexpression of bcl-2 in Epstein-Barr virus-associated gastric carcinoma. Histopathology. 1999:34:502-9.

30. Qiu MZ, Cai MY, Zhang DS, et al. Clinicopathological characteristics and prognostic analysis of Lauren classification in gastric adenocarcinoma in China. J Transl Med. 2013;11:58.

31. Liu X, Liu J, Qiu H, et al. Prognostic significance of Epstein-Barr virus infection in gastric cancer: a meta-analysis. BMC Cancer. 2015;15:782. 
32. Gruhne B, Sompallae R, Marescotti D, et al. The Epstein-Barr virus nuclear antigen-1 promotes genomic instability via induction of reactive oxygen species. Proc Natl Acad Sci USA. 2009;106:2313-8.

33. SchulzTF, Cordes S. Is the Epstein-Barr virus EBNA-1 protein an oncogen? Proc Natl Acad Sci USA. 2009;106:2091-2.

34. Gutierrez MI, Raj A, Spangler G, et al. Sequence variations in EBNA-1 may dictate restriction of tissue distribution of Epstein-Barr virus in normal and tumour cells. J Gen Virol. 1997;78(Pt 7):1663-70.

35. Chang CM, Yu KJ, Mbulaiteye SM, et al. The extent of genetic diversity of Epstein-Barr virus and its geographic and disease patterns: a need for reappraisal. Virus Res. 2009;143:209-21.
36. Hsu JL, Glaser SL. Epstein-Barr virus-associated malignancies: epidemiologic patterns and etiologic implications. Crit Rev Oncol Hematol. 2000;34:27-53.

\section{Publisher's Note}

Springer Nature remains neutral with regard to jurisdictional claims in published maps and institutional affiliations.
Ready to submit your research? Choose BMC and benefit from:

- fast, convenient online submission

- thorough peer review by experienced researchers in your field

- rapid publication on acceptance

- support for research data, including large and complex data types

- gold Open Access which fosters wider collaboration and increased citations

- maximum visibility for your research: over 100M website views per year

At BMC, research is always in progress.

Learn more biomedcentral.com/submissions 